\title{
Simulation of Shakedown Behavior in Pavement's Granular Layer
}

\author{
Behzad Ghadimi, Ainalem Nega, and Hamid Nikraz
}

\begin{abstract}
While in the design of flexible pavement the significance of asphalt layers is understood, the role of granular layers supporting the asphalt layers should not be underestimated. The behavior of granular layers used in base, sub-base or subgrade layer of flexible pavement is complicated due to nonlinear elastoplastic response of materials subjected to dynamic load of traffic. Shakedown theory integrated with Mohr-Coulomb criterion is applied to simulate the response of granular layers to dynamic loading in a numerical analysis. The results of analysis is then compared to simple the results of modeling without considering shakedown effects and the conclusion is drawn.
\end{abstract}

Index Terms-Dynamic analysis, flexible pavement, numerical simulation, shakedown.

\section{INTRODUCTION}

The response of granular particles to different types of loading in a layered flexible pavement system is one of the most formidable issues in numerical simulation of pavement layers. Problematic part is that the response of granular particles is function of parameters such as loading amplitude, weathering, particle's properties and number of cycles.

There have been numbers of studies to investigate the response of granular particles used in pavement structure under dynamic loading through experimental tests. During these studies and also field observation it is understood that during traffic cycles material properties is modified as a function of loading cycle. This observation leads to development of shakedown concept.

The theory of shakedown has been introduced to account for this complex response of materials. One of the first usages of shakedown theory was to predict response of metallic members due to cyclic loading [1].

Then this concept is examined in pavement engineering to simulate unbound granular materials (UGM) used in flexible pavement layers [2], [3]. In these studies shakedown theory is used to indicate the behavior of UGM based on the data provided by AASHO experiment (AASHTO 1986) [4]. After that, the method of limit analysis used to indicate lower and upper bound limits of UGM in shakedown condition. Two of most cited studies are upper-bound solution presented by Collins and Boulbibane[5] and lower-bound solution published by $\mathrm{Yu}$ and Hossain [6]. In the review by

Manuscript received April 4, 2014; revised July 14, 2014. This work was supported in part by the Curtin University under ARC grant. Additional support is provided by AAPA, Cities of Perth, Canning, Swan and Stirling.

The authors are with the Civil Department of Curtin University, GPO Box U1987, Perth, Australia (e-mail: behzad.ghadimi@postgrad.curtin.edu.au, ainalem.nega@postgrad.curtin.edu.au,h.nikraz@curtin.edu.au)
Lekarp [7] the important studies regarding effects of strains development on materials characteristics is published.

Brown et al., [8] reported the results of laboratory modeling of two wheel tracking devices. Then the results of experiment are examined against the analytical results of lower bound shakedown subjected to Mohr-Coulomb criterion.

In an attempt to find out the UGM behavior in large number of loading cycles Siripun et al., [9] investigated crushed rock magterials used as base in flexible pavement in WA and derived experimenta; equation for shakedown behavior of this materials.

And recently Cerni et al., [10] investigated the shakedown behavior of granular mix and provided a new experimental function to correlate the plastic strain to number of cycles.

The experimentally produced shakedown function can be implemented in a constitutive model which represents this specific type of elastoplasticity (shakedown behavior). Then developed constitutive model can be utilized in a numerical simulation to present response of UGM under cyclic loading.

Numerical simulation of UGM has been studied by by Zaghloul and White [11] where ABAQUS software was employed in a dynamic analysis of a flexible pavement layers. In this study a three dimensional model investigated considering Drucker-Prager and Cam-Clay criteria as a predictor of plastic behavior.

Shen and Kirkner [12] investigated the elastoplastic properties of UGM affecting rutting of pavement system. In this research numerical simulation using iterative method and infinite element was manipulated to predict the residual displacement and minimize the influences of conditions. The elastoplastic constitutive model was Drucker-Prager criterion.

Another simulation is conducted by Ling and Liu [13] where the response of reinforced $\mathrm{AC}$ in a plane strain model subjected to monotonic load is investigated. The simulation is run through PLAXIS program and UGM elastoplastic behaviour is considered through Mohr-Coulomb criterion.

Saad et al., [14] examined numerical simulation to be applied in pavement design criteria. In this research tensile strain at the bottom of asphalt layer is representative of fatigue criteria and the vertical strain at the top of subgrade is indicator of rutting criteria. Material elastoplastic behavior is considered through Drucker-Prager model and simulation is run by ADINA.

Chazallon et al., [15] developed new elastoplastic model in isotropic condition considering kinematic hardening. In this model modified Boyce model [16] implemented to account for sand response in which the effects of void ratio and mean stress is considered. 
Then Allu et al., [17] implemented constitutive model presented by Habiballah and Chazallon [18] in a FEM simulation of a low volume traffic road.

Further development is conducted by Chazallon et al. [19] to integrate the previous researches [15], [17] in a FEM modelling considering the Boyce model [16] and shakedown for UGM layers.

In this research the experimental model for UGM shakedown presented by Chazallon et al. is integrated in new constitutive model based on Mohr-Coulomb criterion in a FEM simulation in ABAQUS.

\section{Development of Constitutive Model}

Considering elastic materials (linear or nonlinear) the loading and unloading path in stress-strain domain is the same. That means there is not any residual strain produced in loading cycles. However, dealing with elastoplastic materials if amplitude of loading exceeds the yield criterion there would be some residual strain each loading cycles.

Definition of plastic limit for materials is through introducing constitutive models for those materials. Two widely applied constitutive models to model UGM responses in pavement layers known to be Mohr-Coulomb criteria and Drucker-Prager[20].

$$
\sigma_{1}-\sigma_{3}-\left(\sigma_{1}+\sigma_{3}\right) \sin \varphi-2 \operatorname{ccs} \phi=0
$$

In this equation $\sigma$ and $\varepsilon$ are stress and strain. $I_{1}$ and $J_{2}$ are first invariant of principle stress and second invariant of deviator stress tensor respectively. The granular properties are represented by internal friction angle $(\varphi)$ and apparent cohesion $(c)$.

When the shakedown is not taken into account, progress of plastic strain is only dependent of loading amplitude. In other word with constant amplitude of loading a constant amount of plastic strain is produced in each cycle and plastic strain increases linearly in respect to number of cycle. However, in actual pavement system, UGM demonstrates a different type of behavior in which development of plastic strain is quick in first few cycle of loading, however, it is reduced in time. This is known to be due to compaction and changing materials properties in each cycle.

If induced stress in materials fall in elastic domain the constitutive model $\left(\boldsymbol{C}^{\boldsymbol{e}}\right)$ is identified by only elastic parameters. On the other hand when the stress field exceeds the plastic yield criterion, the constitutive model $\left(\boldsymbol{C}^{e p}\right)$ is indicated by (Mohr-Coulomb or Drucker-Prager).

When materials behave according to the shakedown model its first plastic strains will be indicated from Equation (1) 28 but gradually the constitutive model of materials changes from elastoplastic to purely elastic material. This means that if induced stress of materials fall in shakedown limits, there would be almost no plastic strain after sufficient number of cycles.

The above statement can be written as (2):

$$
\sigma_{i j}^{n}=C_{i j k l}^{n} \varepsilon_{k l}^{n}
$$

The superscript $\mathrm{n}$ and letter $\mathrm{N}$ identify the number of loading cycles.

Now differentiate in terms of time, growth of incremental plastic strain can be stated in (3):

$$
\frac{\partial \varepsilon^{p}}{\partial t}=\frac{\partial f_{i}(N)}{\partial N} \varepsilon_{0}^{p}
$$

where

$$
\left\{\begin{array}{c}
N=1 \Rightarrow \frac{\partial f_{i}(1)}{\partial N}=1 \\
N \rightarrow \infty \Rightarrow \frac{\partial f_{i}(1)}{\partial N}=0
\end{array}\right.
$$

Now based on (3) and (4) Shakedown constitutive model is capable of modification according loading cycles and stress state (compare to the yield surface).

Equation (5) represents newly developed constitutive model for Shakedown materials:

$$
\begin{aligned}
& \left(C_{i j k l}^{n}\right)^{S}=\left(\frac{\partial f_{i}(N)}{\partial N}\right)\left(C_{i j k l}^{n}\right)^{e p}+\left(1-\frac{\partial f_{i}(N)}{\partial N}\right)\left(C_{i j k l}^{n}\right)^{e} \\
& \left(C_{i j k l}^{n}\right)^{S}=\left(\frac{\partial f_{i}(N)}{\partial N}\right)\left(C_{i j k l}^{n}\right)^{e p}+\left(1-\frac{\partial f_{i}(N)}{\partial N}\right)\left(C_{i j k l}^{n}\right)^{e}
\end{aligned}
$$

Superscript $S$ denotes the shakedown constitutive models which is gradually change form elastoplastic constitutive model $\left(\boldsymbol{C}^{e p}\right)$ to purely elastic constitutive model $\left(\boldsymbol{C}^{\boldsymbol{e}}\right)$.

\section{MOdELING OF LAYERED FleXIBLE PAVEMENT}

In this study a firstly the constitutive model is examined against published laboratory data by Habiballah and Chazallon [18]. This step is conducted to verify the constitutive models performance. In this simulation a triaxial cell is simulated in an axisymmetric model by ABAQUS. Then stage of stress configuration is set as that examined by Habiballah and Chazallon [18] is simulated on the model. Fig. 1. Shows the results of developed plastic strain in numerical simulation against published results of laboratory test. The materials properties are demonstrated in Table I.

In this part of simulation a triaxial cylindrical sample in height of $20 \mathrm{~cm}$ and diameter of $10 \mathrm{~cm}$ is modeled by 100

\begin{tabular}{|c|c|c|c|}
\hline UGM Properties & & & \\
\hline Elastic & \multicolumn{2}{|c|}{$\begin{array}{l}\text { Elastic Moduli } \\
E=200 \mathrm{MPa}\end{array}$} & $\begin{array}{c}\text { Poisson Ratio } \\
v=0.2\end{array}$ \\
\hline Plastic & $\varphi=44^{\circ}$ & $c=12.26 \mathrm{kPa}$ & $\varphi_{\text {dilation }}=39^{\circ}$ \\
\hline
\end{tabular}
linear quadrilateral elements of CAX4R. The stress ratio is defined by the ratio of deviator stress $\left(q=\sigma_{1}-\sigma_{3}\right)$ to confining pressure $\left(p=\sigma_{1}+2 \sigma_{3}\right)$. In this simulation the $q / p$ is defined to be Habiballah and Chazallon[18].

TABLE I: PROPERTIES OF UGM USED FOR VERIFICATION

In the next step of the simulation 3 layers flexible pavement is modeled in ABAQUS. In this simulation a uniformly distributed pressure of $750 \mathrm{kPa}$ applied over 
circular area with the radius of $9.2 \mathrm{~cm}$ is modeled. The pressure and loading area is selected according to AUSTROAD design load. A total medium of $10 \mathrm{~m} \times 20 \mathrm{~m}$ is modeled as illustrated in Fig. 2. The dimension of medium should be in a way that the results of deformation around loading tire are not affected by the boundary condition. To meet this condition Duncan et al., [21] suggested that the boundaries need to be at 50-times $\mathrm{R}$ (loading radius) in vertical and 12-times $\mathrm{R}$ in horizontal direction. In $2009 \mathrm{Kim}$ et al., [22] modeled an ABAQUS simulation for an axisymmetric model and stated that effects of boundary conditions will be negligible if a medium of $140-\mathrm{R}$ in vertical and $20-\mathrm{R}$ in horizontal direction is considered for modeling. In this study the dimension of model is selected to be $111-\mathrm{R}$ in horizontal and 222-R in vertical direction which obviously satisfy the previous suggestion. Moreover, a set of infinite element is implemented in side of the model to simulate the infinite space in horizontal direction.

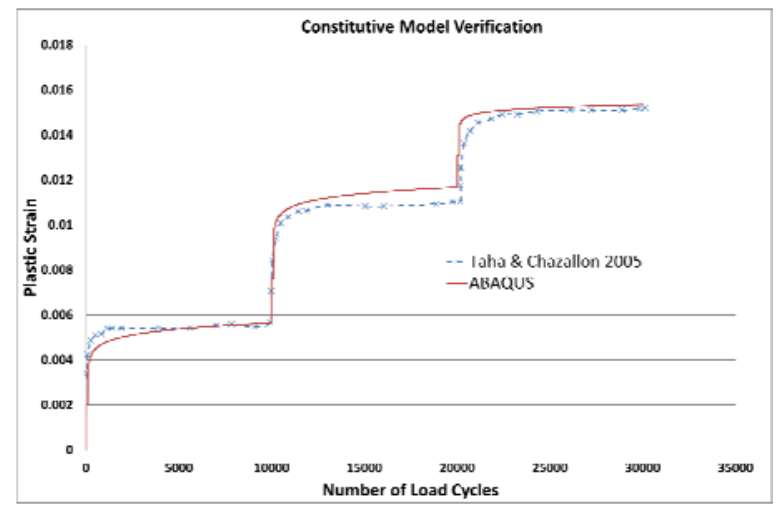

Fig. 1. Development of plastic strains (verification)

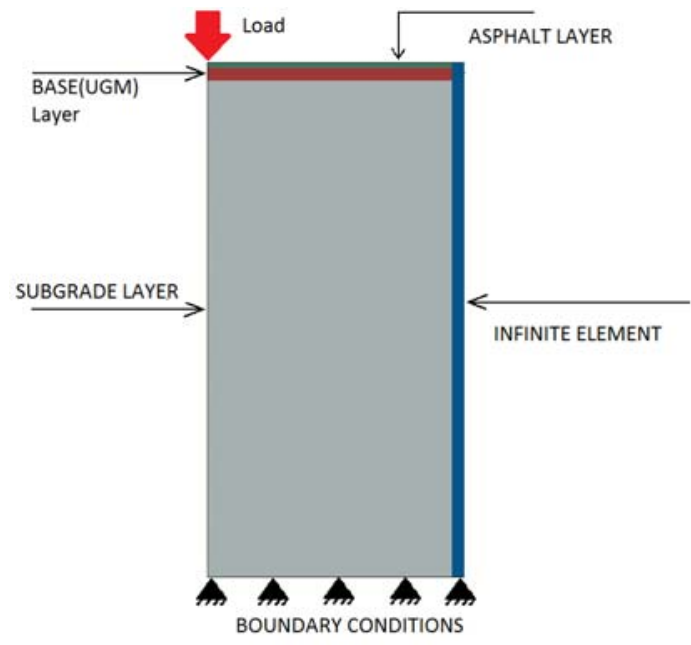

Fig. 2. FEM model of layered flexible pavement.

The asphalt concrete is modeled as linear elastic materials in $20 \mathrm{~cm}$ thickness. The subgrade layer is modeled according to Drucker-Prager constitutive models. Infinite elements also assume linear elastic behavior in far field. Table II represents the materials properties in each layer. For the base layer (UGM) two different constitutive models are implemented for a $50 \mathrm{~cm}$ thickness. First the constitutive model according to simple Mohr-Coulomb criterion is modeled. Here the return mapping algorithm introduced by Clausen et al., [23] is coded in UMAT and inserted as UGM constitutive model. In the second simulation effect of shakedown as stated in (5) is studied. Table II represents the properties of materials used for simulation.

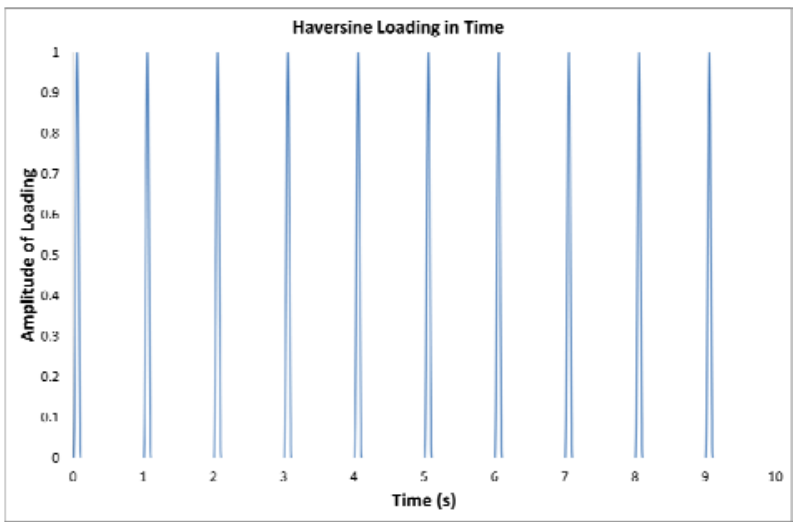

Fig. 3. Haversine periodic loading.

The dynamic finite element simulation is conducted in implicit scheme formulation. Loading is assumed to be a haversine periodical pressure in $10 \mathrm{~s}$. It is a $0.1 \mathrm{~s}$ loading time followed by $0.9 \mathrm{~s}$ rest period. The loading cycles are illustrated in Fig. 3. In this simulation, pressure load of tire gradually increased to a maximum according to haversine function and then decreased to zero. Then it is followed by 0.9 s rest period in which strains continue to develop due to unloading stress distribution.

TABLE II: MATERIALS’ PROPERTIES IN FleXIBLE PAVEMENT MOdEL

\begin{tabular}{cc}
\hline \hline Layer & Properties of Materials \\
\hline Asphalt $-20 \mathrm{~cm}$ & $E=2800 \mathrm{MPa}, v=0.4$, Density $=2200 \mathrm{~kg} / \mathrm{m}^{3}$ \\
Base $-50 \mathrm{~cm}$ & $\mathrm{E}=500 \mathrm{MPa}, v=0.3$, Density $=1800 \mathrm{~kg} / \mathrm{m} 3$ \\
& $\begin{array}{c}\varphi=35^{\circ}, c=7.0 \mathrm{kPa}, \quad \varphi_{\text {dilation }}=17^{\circ} \\
\text { Subgrade }\end{array}$ \\
& $\mathrm{E}=50 \mathrm{MPa}, v=0.35$, Density $=1700 \mathrm{~kg} / \mathrm{m} 3$ \\
& $\varphi=20^{\circ}, c=7.0 \mathrm{kPa}, \quad \varphi_{\text {dilation }}=15^{\circ}$ \\
\hline \hline
\end{tabular}

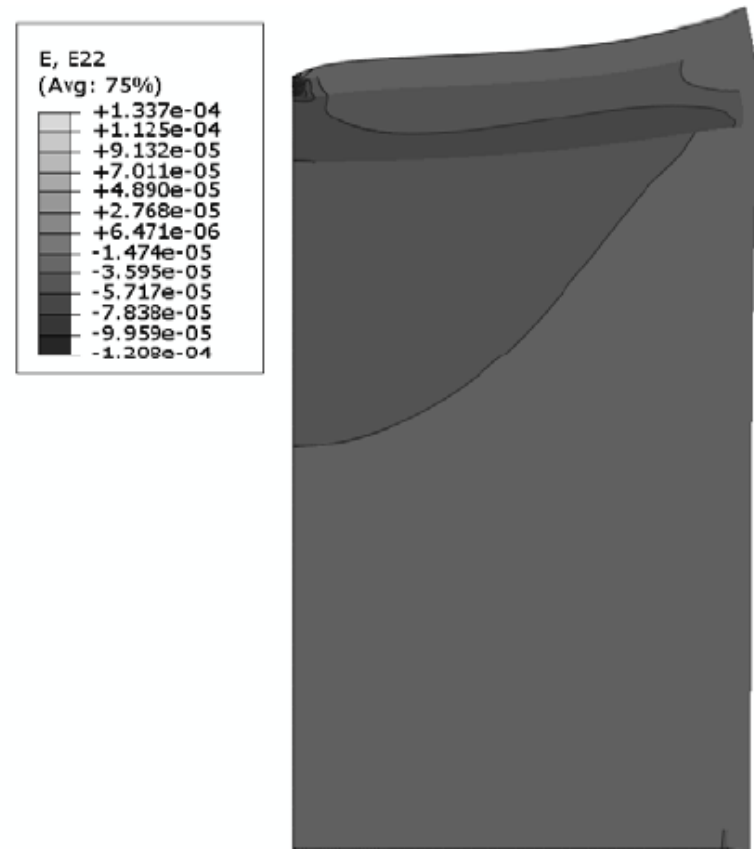

Fig. 4. Total vertical strain in mohr-coulomb model.

Both models are consisting of 15096 elements including 
CAX4R (layered medium) and CINAX4 (infinite space) elements.

\section{SHAKEDOWN RESPONSE OF UGM LAYER}

In this part, results of analysis of two simulations are displayed. As described in previous section two different materials constitutive models is applied for UGM materials used in base layer. For the purpose of scientific comparison the properties and geometry of other layers are the same.

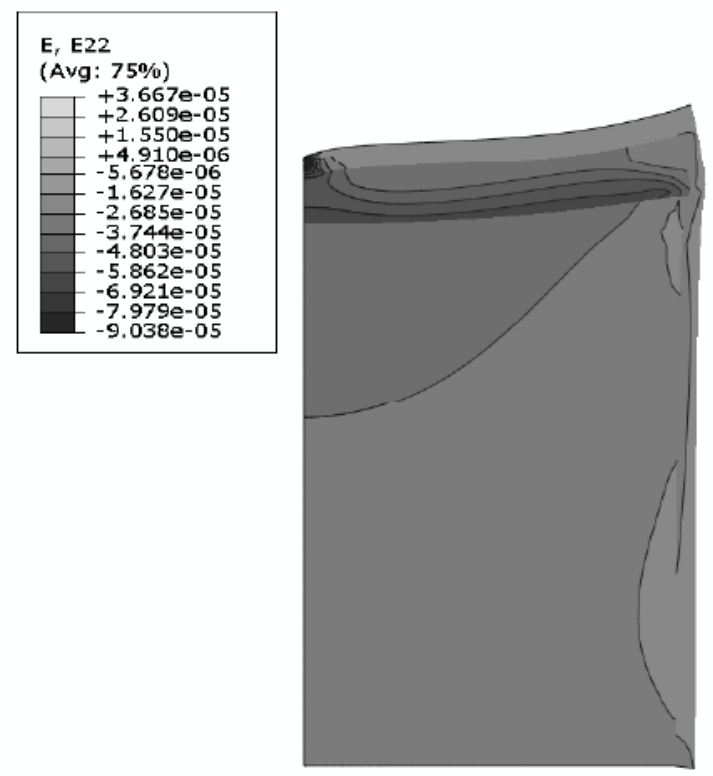

Fig. 5. Total vertical strain in shakedown model.

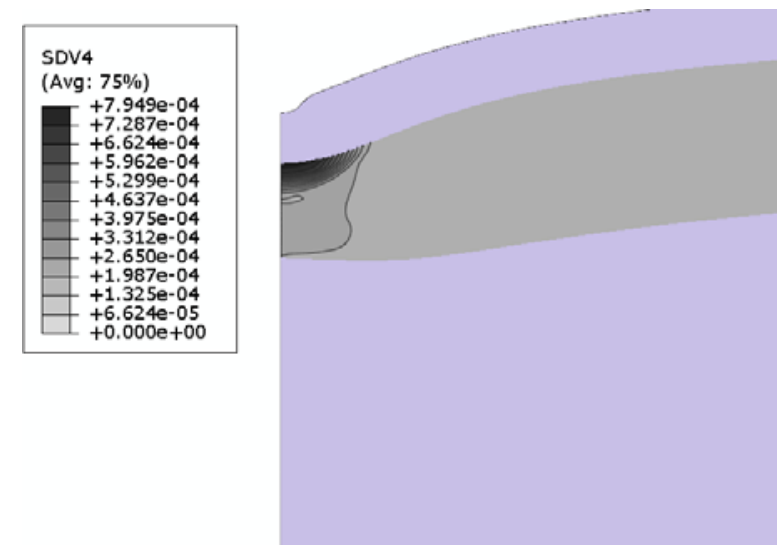

Fig. 6. Total equivalent plastic strain in mohr-coulomb model.

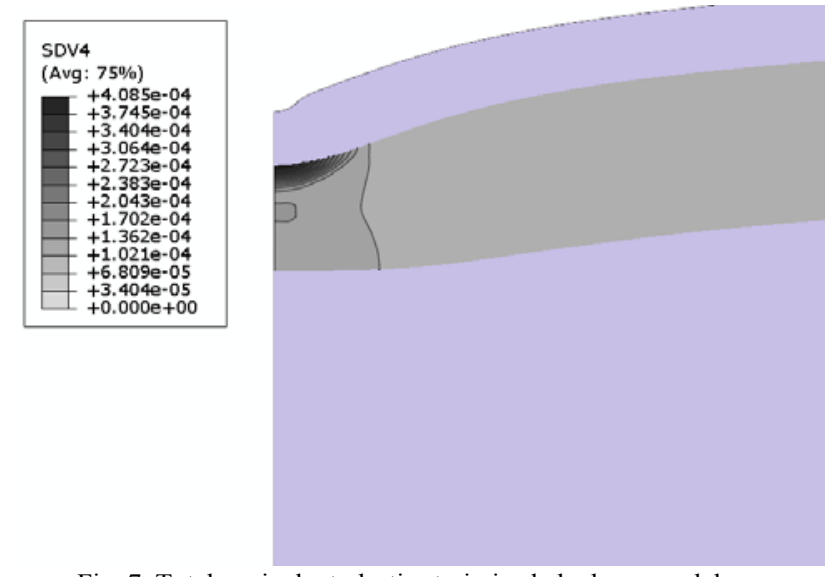

Fig. 7. Total equivalent plastic strain in shakedown model.
In Fig. 4 and Fig. 5 the total vertical strain developed in the model for simple Mohr-Coulomb criterion and Shakedown constitutive model is presented respectively. The results are presented for the last pick of loading ( $9.05 \mathrm{~s})$ to illustrate the accumulated strains. As it can be observed from the contours' range the shakedown model resulted in considerably less strains (limits from $-9.04 \times 10^{-5}$ to $3.67 \times 10^{-5}$ ) in comparison with simple Mohr-Coulomb (limits from $-1.21 \times 10^{-5}$ to $1.34 \times 10^{-5}$ ). It should be noted that the value of the vertical strain in design of flexible pavement is one of the critical value through which the rutting of the pavement is controlled. Therefore the results may be interpreted that not considering shakedown effect may lead to a conservative overdesign when rutting is the controlling criterion.

In Fig. 6 and Fig. 7 the distribution of equivalent plastic strain is demonstrated. The exact definition of equivalent plastic strain for Mohr-Coulomb criterion plasticity is defined by (6)

$$
\bar{\varepsilon}^{p l}=\int \frac{1}{c} \sigma: d \varepsilon^{p l}
$$

where $c$ indicates materials cohesion; $\sigma$ is stress tensor and $d \varepsilon^{p l}$ is tensor of incremental plastic strain. This value indicates the magnitude of the plastic strain in each element.

The contours of equivalent plastic strain indicate different distribution of plastic strains. More importantly a meaningful difference between the highest values in each of the model is visible. While in simple Mohr-Coulomb materials the equivalent plastic strain reach to $7.95 \times 10^{-4}$ almost half of the amount is calculated when the effects of shakedown is taken into account $\left(4.08 \times 10^{-4}\right)$.

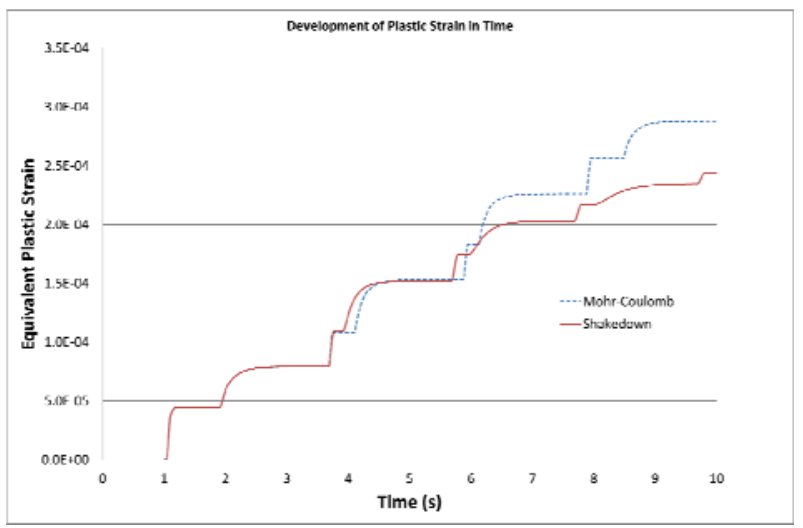

Fig. 8. Development of equivalent plastic strain in time.

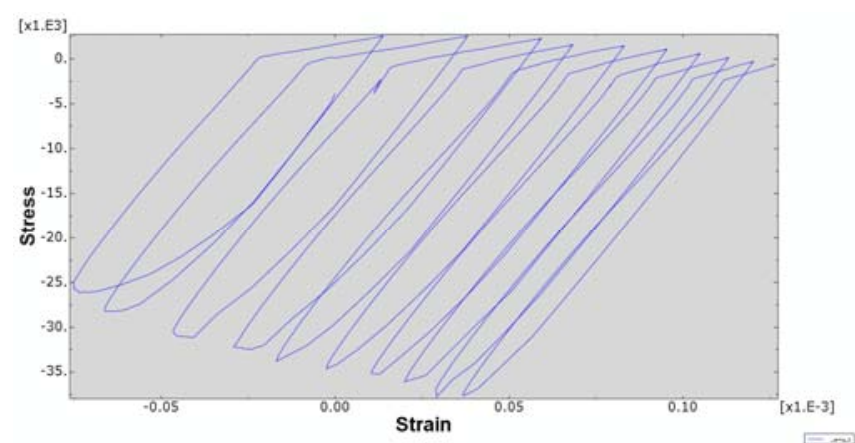

Fig. 9. Stress-strain hysteresis loop during shakedown. 
To investigate the effect of shakedown behaviour more closely, the second element exactly beneath the asphalt layer in center of loading is selected. This element experiences the highest vertical stress during loading cycles. Fig. 8 illustrates the development of equivalent plastic strain in center of this element during the loading time in both Mohr-Coulomb and shakedown models.

As it can be seen from this figure, equivalent plastic strain in shakedown model is less than those developed in Mohr-Coulomb model. It should also be noted that this study conducted a dynamic analysis in 10s time period. However, the effects of shakedown causes more difference if the longer period of loading time is simulated.

The accumulated equivalent plastic strain reaches to the maximum of $2.89 \times 10^{-4}$ for Mohr-Coulomb materials while it is $2.43 \times 10^{-4}$ in shakedown model.

The behaivour is more deeply understood if the hysteresis loops of stress-strain are considered. In Fig. 9 the hysteresis loops for the second element below the asphalt concrete is demonstrated for shakedown model. As it can be seen loops intend to produce less closed area. In other words the behaviour of materials is going towards elastic behaviour.

Such a response can be understood as the materials shakedown response which differs from the simple Mohr-Coulomb plastic criterion. According to this model materials behave stiffer (the stress-strain curve inclined towards a line) due to increase of loading cycles.

\section{CONCLUSION}

In this paper a new constitutive model capable of considering shakedown effects in unbound granular materials used in base layer of a sample flexible pavement is investigated. In the first step implementation of constitutive model is verified against the published results of laboratory measured shakedown for granular materials. Then constitutive model is numerically implemented in a dynamic finite element simulation and the results are compared to the results of simple Mohr-Coulomb criterion. Based on the results, considering shakedown effects reduces the calculated strain (especially plastic strains) according to the cycles of loading. The effect can have significant influence specifically in modeling traffic loading on the pavement structure. In the calculated vertical strain of the base layer a reduction of 50\% is observed for the shakedown model compare to simple Mohr-Coulomb after 10s of loading. This intensifies the necessitation of considering shakedown effects in simulation of pavement layers.

\section{REFERENCES}

[1] J. Zarka and J. Casier, "Elastic plastic response of structure to cyclic loading: practical rules," Mechanics today, vol. 4, pp. 93-198, 1979.

[2] R. Sharp, "Pavement design based on shakedown analysis," Transportation Research Record, vol. 1022,1985.

[3] R. W. Sharp and J. R. Booker, "Shakedown of pavements under moving surface loads," Journal of Transportation Engineering, vol. 110, p. 1, 1984.

[4] B. C. Bodhinayake, "A study on nonlinear behaviour of subgrades under cyclic loading for the development of a design chart for flexible pavements," Ph.D. dissertation Dep. Civil Eng.,University of Wollongong, Wollongong, NSW, 2008.
[5] I. Collins and M. Boulbibane, "The application of shakedown theory to pavement design," Metals and Materials, vol. 4 no. 4, pp. 832-837, 1998..

[6] H. Yu and M. Hossain, "Lower bound shakedown analysis of layered pavements using discontinuous stress fields," Computer Methods in Applied Mechanics and Engineering, vol. 167 no. 3, pp. 209-222, 1998.

[7] F. Lekarp, U. Isacsson, and A. Dawson, "State of the art. II: Permanent strain response of unbound aggregates," Journal of Transportation Engineering, vol. 126, no. 1, pp. 76-832000..

[8] S. Brown, S. Juspi, and H. Yu. "Experimental observations and theoretical predictions of shakedown in soils under wheel loading," in Proc. the 1st International Conference on Transportation Geotechnics, Nottingham, UK, 2008, pp. 25-27.

[9] K. Siripun, P. Jitsangiam, and H. Nikraz, "Permanent deformation behaviour and model of crushed rock base," Australian Journal of Civil Engineering, vol. 8, no.1, 2010.

[10] G. Cerni et al., "Characterisation of permanent deformation behaviour of unbound granular materials under repeated triaxial loading," Construction and Building Materials, vol. 28, no. 1, pp. 79-87, 2012.

[11] S. Zaghloul and T. White, "Use of a three-dimensional, dynamic finite element program for analysis of flexible pavement," Transportation Research Record, vol. 1388, pp. 60-69, 1993.

[12] W. Shen and D. J. Kirkner, "Non-linear finite-element analysis to predict permanent deformations in pavement structures under moving loads," International Journal of Pavement Engineering, vol. 2, no. 3, pp. 187-199, 2001

[13] H. I. Ling and H. Liu, "Finite element studies of asphalt concrete pavement reinforced with geogrid," Journal of Engineering Mechanics, vol. 129, no. 7, pp. 801-811, 2003.

[14] B. Saad, H. Mitri, and H. Poorooshasb, "Three-dimensional dynamic analysis of flexible conventional pavement foundation," Journal of transportation engineering, vol. 131, no. 6, pp. 460-469, 2005.

[15] C. Chazallon, P. Hornych, and S. Mouhoubi, "Elastoplastic Model for the Long-Term Behavior Modeling of Unbound Granular Materials in Flexible Pavements," International Journal of Geomechanics, vol. 6, no. 4, pp. 279-289, 2006

[16] J. Boyce, S. Brown, and P. Pell, "The resilient behaviour of a granular material under repeated loading," Australian Road Research Board Conference Proc., 1976, vol. 8, no. 1

[17] F. Allou, C. Chazallon, and P. Hornych, "A numerical model for flexible pavements rut depth evolution with time," International Journal for Numerical and Analytical Methods in Geomechanics, vol. 31, no. 1, pp. 1-22, 2007.

[18] T. Habiballah and C. Chazallon, "An elastoplastic model based on the shakedown concept for flexible pavements unbound granular materials," International Journal for Numerical and Analytical Methods in Geomechanics, vol. 29, no. 6, pp. 577-596, 2005.

[19] C. Chazallon et al., "Finite elements modelling of the long-term behaviour of a full-scale flexible pavement with the shakedown theory," International journal for numerical and analytical methods in geomechanics, vol. 33, no. 1, pp. 45-70, 2009.

[20] H. S. Yu, Plasticity and Geotechnics, Springer, vol. 1, 2006, pp. 75-80.

[21] J. M. Duncan, C. L. Monismith, and E. L. Wilson, "Finite element analyses of pavements," Highway Research Record, vol. 228, Highway Research Board, Washington D.C., pp. 18-33,1968.

[22] M. Kim, E. Tutumluer, and J. Kwon, "Nonlinear pavement foundation modeling for three-dimensional finite-element analysis of flexible pavements," International Journal of Geomechanics, vol. 9, no.5, pp. 195-208, 2009.

[23] J. Clausen, L. Damkilde, and L. Andersen, "An efficient return algorithm for non-associated plasticity with linear yield criteria in principal stress space," Computers and Structures, vol. 85, no. 23, pp. 1795-1807.

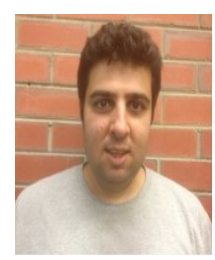

Behzad Ghadimi was born in Tehran, Iran in 1983. $\mathrm{He}$ is an Iranian Civil Engineer, has a MSc. in the geotechnical engineering in 2008 from Sharif University, Tehran, Iran. He has joined Curtin University from 2011 as a scholarship awarded PhD student under supervision of Prof. Hamid Nikraz. He has published 9 papers in refereed journals and conferences in the area of numerical pavement modeling. His main carrier in MSc. and $\mathrm{PhD}$. has been the numerical and computational modeling of geomaterials. He has a three years industrial experience doing FEM modeling in some important structures in Iran. 


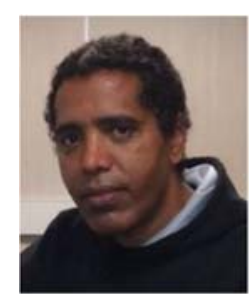

Ainalem Nega is currently a PhD Candidate in civil engineering at Curtin University in Perth, Western Australia. He has completed a master of engineering science (hydrology)-research degree in 2011 from the University of Western Australia. He also holds a bachelor of engineering (mining and environmental engineering) degree from the Western Australia School of Mines, Curtin University of Technology in 2007. He is currently working as a sessional lecturer at Curtin University in Perth, Western Australia while he is also studying his $\mathrm{PhD}$ in civil engineering. He was a sessional lecturer at the Western Australia School of Mines (WASM) in 2011 and was involved on Casual Academic Teaching and Tutoring at the University of Western Australia since 2008 till his MEngSC-Research degree finished in 2011. He had also worked with SGS Lakefield Oretest Pty.Ltd, Operating Uranium Pilot Plant and Kimberley Diamond Company (Vacation Student Employment) in Australia in 2011 and 2006 and other NGO's such as UNHER, LWF and Norwegian Save the Children as Supervisor in Kenya.
Hamid Nikraz is a professor and the head at the Department of Civil Engineering, School of Engineering, Curtin University of Technology, Australia. Prior to his academic career he had many years' experience working in industry in the Middle East, Europe and Australia. He has provided numerous consultancy services in his field to over 200 organizations nationally and internationally. He obtained his $\mathrm{PhD}$ at Curtin University of Technology in 1989. Dr Nikraz is a Fellow Member of the Institution of Engineers, Australia. He has guided $59 \mathrm{PhD}$ thesis, 26 masters students and published over 400 publications in various journals, books and conference proceedings. Professor Nikraz has initiated research works in the area of Geopolymers, Concrete, Soil Stabilisation and Pavement Engineering. Professor Nikraz is also a reviewer of many national and international journals. 